\title{
Improvement of renal profile in Gentamicin-induced Nephrotoxicity in albino wistar rats by edible macrofungi Dacryopinax spathularia and Schizophyllum commune
}

\author{
Amar Kumar* \\ Department of Zoology, K. S. College, Kolhan University, Chaibasa (Jharkhand), India \\ Manoj Kumar \\ Department of Zoology, St. Xavier's College, Ranchi (Jharkhand), India \\ Sukumar Dandapat \\ Department of Zoology, Ranchi University, Ranchi (Jharkhand), India \\ Rakesh Ranjan \\ Department of Zoology, Ranchi University, Ranchi (Jharkhand), India \\ M. P. Sinha \\ Department of Zoology, Ranchi University, Ranchi (Jharkhand), India \\ *Corresponding author. E-mail: amarzoology3@gmail.com
}

\begin{abstract}
The present work has been taken to assess the pharmacological efficacy of two edible macrofungi Dacryopinax spathularia and Schizophyllum commune in the improvement of renal profile of Gentamicin-induced nephrotoxicity in albino wistar rats. The intraperitoneal administration of gentamicin $80 \mathrm{mg} / \mathrm{Kg}$ Body Weight per day had resulted in alterations in renal function and renal damage which was reflected by abnormal and significant $(p=0.05)$ increase in renal function parameters of blood like Urea, Creatinine, Uric Acid and Blood Urea Nitrogen (BUN). On administration of high dose (500 mg/Kg BW) of $D$. Spathularia extract to the nephrotoxic group of rats the concentration of urea, creatinine, uric acid and BUN significantly decreased from $104.26 \pm 7.45$ to $76.27 \pm 7.24$, $1.17 \pm 0.43$ to $0.68 \pm 0.47,3.68 \pm 1.34$ to $2.58 \pm 0.56$ and $48.72 \pm 4.36$ to $31.14 \pm 3.76$ respectively, in comparison to the nephrotoxic group of rats. On the other hand, the administration of high dose $(500 \mathrm{mg} / \mathrm{Kg} \mathrm{BW})$ of $S$. commune extract to the nephrotoxic group of rats resulted into significant $(\mathrm{p}=0.05)$ decrease in the concentration of urea, creatinine, uric acid and BUN, from $104.26 \pm 7.45$ to $51.42 \pm 6.15,1.17 \pm 0.43$ to $0.62 \pm 0.14,3.68 \pm 1.34$ to $2.36 \pm 0.74$ and $48.72 \pm 4.36$ to $28.65 \pm 3.85$ respectively, in comparison to the nephrotoxic group of rats. The results also revealed that $S$. commune extract showed comparatively more efficacy in the renal profile improvement of nephrotoxic rats in comparison to the $D$. spathularia extract.
\end{abstract}

Keywords: Dacryopinax spathularia, Gentamicin, Macrofungi, Nephrotoxicity, Oxidative stress, Schizophyllum commune.

\section{INTRODUCTION}

Kidneys or Renal organs are paired organs carrying out many vital physiological functions in the body like maintaining the homeostasis, excretion of waste products, maintaining the $\mathrm{pH}$, regulation of blood pressure, secretion of some active compounds etc. Therefore any serious nephropathological condition may cause serious health problems and may prove fatal for the individual. Gentamicin is an aminoglycoside, frequently used as antibiotic drug against gram negative bacterial infections, which may include bone infections, meningitis, pneumonia, urinary tract infections, sepsis etc. (Gilbert, 2005). However, on the other side of its medicinal uses, gentamicin causes dose-dependent serious adverse effects on renal

\section{Article Info}

DOI:10.31018/jans.v11i2.2088 Received: April 18, 2019

Revised: May 26, 2019

Accepted: May 30, 2019

\section{How to Cite}

Kumar, A. et al. (2019).

Improvement of renal pro-

file in Gentamicin-induced Nephrotoxicity in albino wistar rats by edible macrofungi Dacryopinax spathularia and Schizophyllum commune. Journal of Applied and Natural Science, 11(2): 436 - 439

https://doi.org/10.31018/ jans.v11i2.2088 
induced nephrotoxicity is associated with the development of oxidative stress by the generation of free radicals like ROS (Reactive Oxygen Species) associated with the depletion of antioxidant molecules in the kidney (Reiter et al., 2002; Balakumar et al., 2008; Ozbek, 2012). Several studies have suggested the drugs with antioxidant capacity for their application as nephroprotective agents against gentamicin-induced nephrotoxicity (AbdelRaheem et al., 2009; Harlalka et al., 2007).

The mushrooms or macrofungi are known to be rich sources of various bioactive substances like tannins, saponins, alkaloids, flavonoids, phenolics, terpenoids etc., which are having various types of significant pharmacological activities including markable antioxidant properties. The therapeutic efficacy of macrofungi have also been extensively reviewed by Lindequist et al (2005). Dacryopinax spathularia (Schwein) and Schizophyllum commune (Fries) are two edible macrofungi belonging to group Basidiomycota and are among the commonly used traditional neutraceutical dietary sources, especially in north-eastern region of India, as antibacterial, anti-inflammatory, anti-diabetic, hepatoprotective and nephroprotective food supplement. The biochemical composition and the antioxidant activity of $D$. spathularia and $S$. commune have been reported by Kumar et al (2018). The Hepatoprotective efficacy of the edible macrofungi $D$. spathularia and $S$. commune has also been reported by Kumar et al (2019). Keeping in view that the gentamicin-induced nephrotoxicity is being associated with the development of oxidative stress and these two edible macrofungi have significant antioxidant efficacy, the present work was taken to assess the nephroprotective activity of these macrofungi using albino wistar rats as animal model.

\section{MATERIALS AND METHODS}

Animals: In the present study, Wistar albino rats were used, weighing about $175-200 \mathrm{~g}$. The animals were maintained under standard laboratory conditions under temperature maintained at $25 \pm 5^{\circ} \mathrm{C}$, Dark-Light cycle of $12 \mathrm{hrs}$., relative humidity of $50 \pm 15 \%$, throughout the experimental period of time. The commercial pellet diet was used to fed the animals and water was supplied ad libitum. Polypropylene cages were used to house the animals and paddy husk was used as bedding material in a well-ventilated room. The experiment was carried out as per the approval of Ethics committee of Ranchi University, Ranchi.

Acute toxicity studies: The acute toxicity studies has been done according to the OECD guidelines (2004). Two groups of 10 rats each were formed and each group received different doses of one macrofungal extract. The animals were fed the extract orally by using oral feeding tube. Within 48 hrs. no mortality was observed up to the doses of
$2000 \mathrm{mg} / \mathrm{kg}$ body weight (BW) /day.

Induction of nephrotoxicity and evaluation of improvement in renal profile: After acclimatization, Nephrotoxicity was induced by intraperitoneal administration of $80 \mathrm{mg} / \mathrm{Kg} \mathrm{BW}$ (Body Weight) per day of Gentamicin for 10 consecutive days. The rats were divided into six groups of six rats each and the experiment was carried out as follows:

Group 1: Control group, received $1 \mathrm{ml}$ of distilled water orally

Group 2: Nephrotoxic group, received intraperitoneal (i.p.) injection of i.p. of Gentamicin 80 $\mathrm{mg} / \mathrm{Kg}$ BW per day

Group 3: Nephrotoxic, received $250 \mathrm{mg} / \mathrm{Kg}$ BW/ day of $D$. spathularia extract (LD) one hour post gentamicin injection; LD= Low Dose

Group 4: Nephrotoxic rats, received $500 \mathrm{mg} / \mathrm{Kg}$ BW/day of $D$. spathularia extract (HD) one hour post gentamicin injection; HD= High Dose

Group 5: Nephrotoxic rats, received $250 \mathrm{mg} / \mathrm{Kg}$ BW/ day of $S$. commune extract (LD) one hour post gentamicin injection

Group 6: Nephrotoxic rats, received 500 mg/Kg BW/day of $S$. commune extract (HD) one hour post gentamicin injection

Sample collection and assessment of biochemical parameters: The experimental procedure as stated above was continued for 10 consecutive days. After 10 days, the animals were starved overnight and then collection of blood was done by puncturing the retro-orbital plexus under light ether anesthesia without sacrificing the animals. Three blood samples were collected in, randomly from each group. The blood samples were taken in test tubes, allowed to clot for 30 minutes and then centrifuged at $2500 \mathrm{rpm}$ for 10 minutes to get the clear serum for biochemical investigations. The renal activity marker blood parameters like Urea, Uric acid, Creatinine and BUN (Blood Urea Nitrogen) were estimated by Autoanalyser (cobas c311, Roche diagnostics, Japan) with the help of standard kits.

Statistical analysis: All data was taken in triplicate and presented as mean \pm standard error of mean. The obtained data was statistically analyzed by one way ANOVA, which was followed by student's t-test. The difference of the values was considered significant at $p<0.05$.

\section{RESULTS AND DISCUSSION}

Gentamicin-induced nephrotoxicity is associated with increased rate of generation of free radicals like reactive oxygen species such as hydroxyl radicals, super-oxide anions etc. (Parlakpinar et al., 2005; Sener et al., 2002). The reactive oxygen species can produce cellular injury or necrosis through membrane lipid peroxidation, DNA damage or protein alterations (Arivazhagan and Vimaastalin, 2014). The renal damage or altera- 
Kumar, A. et al. / J. Appl. \& Nat. Sci. 11(2): 436 - 439 (2019)

Table 1. Nephroprotective efficacy of Dacryopinax spathularia extract against Gentamicin-induced nephrototoxicity in rats (Data expressed as mean $\pm S E, n=3$ ).

\begin{tabular}{|c|c|c|c|c|}
\hline Animal Groups & Urea (mg/dL) & $\begin{array}{l}\text { Creatinine } \quad(\mathbf{m g} / \\
\mathrm{dL})\end{array}$ & Uric acid (mg/dL) & BUN (mg/dL) \\
\hline Group 1 (Control) & $46.83 \pm 8.61$ & $0.54 \pm 0.16$ & $2.14 \pm 0.38$ & $22.09 \pm 3.89$ \\
\hline $\begin{array}{l}\text { Group } 2 \text { (Gentamicin treated } \\
\text { Nephrotoxic) }\end{array}$ & $104.26 \pm 7.45^{\mathrm{a}}$ & $1.17 \pm 0.43^{\mathrm{a}}$ & $3.68 \pm 1.34^{\mathrm{a}}$ & $48.72 \pm 4.36^{\mathrm{a}}$ \\
\hline $\begin{array}{l}\text { Group } 3 \text { (Nephrotoxic + LD of D. } \\
\text { Spathularia extract) }\end{array}$ & $88.36 \pm 6.34^{\mathrm{ab}}$ & $0.84 \pm 0.52^{\mathrm{ab}}$ & $2.87 \pm 0.64^{\mathrm{ab}}$ & $38.16 \pm 3.14^{\mathrm{ab}}$ \\
\hline $\begin{array}{l}\text { Group } 4 \text { (Nephrotoxic + HD of D. } \\
\text { Spathularia extract) }\end{array}$ & $76.27 \pm 7.24^{\mathrm{ab}}$ & $0.79 \pm 0.47^{\mathrm{ab}}$ & $2.58 \pm 0.56^{\mathrm{ab}}$ & $31.14 \pm 3.76^{\mathrm{ab}}$ \\
\hline
\end{tabular}

${ }^{a}$ Statistically significant when compared to control group $(p<0.05)$; ${ }^{b}$ Statistically significant when compared to nephrotoxic group $(p<0.05)$.

Table 2. Nephroprotective efficacy of $S$. commune extract against Gentamicin-induced nephrototoxicity in rats (Data expressed as mean $\pm S E, n=3$ ).

\begin{tabular}{lllll}
\hline Animal Groups & Urea $(\mathbf{m g} / \mathbf{d L})$ & Creatinine $(\mathbf{m g} / \mathbf{d L})$ & Uric acid $(\mathbf{m g} / \mathbf{d L})$ & $\mathrm{BUN}(\mathbf{m g} / \mathbf{d L})$ \\
\hline Group 1 (Control) & $46.83 \pm 8.61$ & $0.54 \pm 0.16$ & $2.14 \pm 0.38$ & $22.09 \pm 3.89$ \\
Group 2 (Gentamicin treated & $104.26 \pm 7.45^{\mathrm{a}}$ & $1.17 \pm 0.43^{\mathrm{a}}$ & $3.68 \pm 1.34^{\mathrm{a}}$ & $48.72 \pm 4.36^{\mathrm{a}}$ \\
$\begin{array}{l}\text { Nephrotoxic) } \\
\text { Group 3 (Nephrotoxic + LD of }\end{array}$ & $71.36 \pm 5.12^{\mathrm{ab}}$ & $00.73 \pm 0.27^{\mathrm{ab}}$ & $3.06 \pm 0.78^{\mathrm{ab}}$ & $32.57 \pm 3.28^{\mathrm{ab}}$ \\
$\begin{array}{l}\text { S. commune extract) } \\
\text { Group 4 (Nephrotoxic + HD of }\end{array}$ & $50.42 \pm 6.15^{\mathrm{b}}$ & $0.62 \pm 0.14^{\mathrm{b}}$ & $2.36 \pm 0.74^{\mathrm{b}}$ & $28.65 \pm 3.85^{\mathrm{ab}}$ \\
S. commune extract) & & & &
\end{tabular}

tion in normal functioning of kidney results in abnormal levels of renal function parameters of blood like Urea, Uric acid, Serum creatinine and BUN (Pragati et al., 2018). Many previous workers have reported the nephroprotective efficacy of several natural products of plant or animal origin through their antioxidant activities against Gentamicin-induced nephrotoxicity in albino rats (Saud et al., 2012; Nair et al., 2018).

Table 1 shows the results of assessment of nephroprotective efficacy of $D$. spathularia extract. The results clearly revealed that the concentration of renal function marker serum biochemical parameters like Urea, Creatinine, Uric acid and Blood Urea Nitrogen (BUN) significantly increased $(p=0.05)$ from the normal levels of $46.83 \pm 8.61$ to $104.26 \pm 7.45,0.54 \pm 0.16$ to $1.17 \pm 0.43,2.14 \pm 0.38$ to $3.68 \pm 1.34$ and $22.09 \pm 5.89$ to $48.72 \pm 4.36$ respectively in the Gentamicin-induced nephrotoxic group of rats (group 2) in comparison to the normal control group of rats (group 1). On administration of low dose $(250 \mathrm{mg} / \mathrm{Kg} \mathrm{BW})$ of $D$. Spathularia extract to the nephrotoxic group of rats (group 3 ) the concentration of Urea, Creatinine, Uric acid and BUN significantly decreased from $104.26 \pm 7.45$ to $88.36 \pm 6.34,1.17 \pm 0.43$ to $0.78 \pm 0.52, \quad 3.68 \pm 1.34$ to $2.87 \pm 0.64$ and $48.72 \pm 4.36$ to $32.16 \pm 3.14$ respectively. On administration of high dose $(500 \mathrm{mg} / \mathrm{Kg} \mathrm{BW})$ of $D$. Spathularia extract to the nephrotoxic group of rats (group 4) ) the concentration of Urea, Creatinine, Uric acid and BUN significantly decreased from $104.26 \pm 7.45$ to $76.27 \pm 7.24,1.17 \pm 0.43$ to $0.68 \pm 0.47, \quad 3.68 \pm 1.34$ to $2.58 \pm 0.56$ and $48.72 \pm 4.36$ to $31.14 \pm 3.76$ respectively, in comparison to the nephrotoxic group of rats.

The results of assessment of nephroprotective activity of $S$. commune extract has been shown in table 2. On administration of low dose $(250 \mathrm{mg} / \mathrm{Kg}$ BW) of $S$. commune extract to the nephrotoxic group of rats (group 3) the concentration of Urea, Creatinine, Uric acid and BUN significantly decreased from $104.26 \pm 7.45$ to $71.36 \pm 5.12$, $1.17 \pm 0.43$ to $0.73 \pm 0.27,3.68 \pm 1.34$ to $2.96 \pm 0.78$ and $48.72 \pm 4.36$ to $32.57 \pm 3.28$ respectively. On administration of high dose $(500 \mathrm{mg} / \mathrm{Kg} \mathrm{BW})$ of $S$. commune extract to the nephrotoxic group of rats (group 4) the concentration of Urea, Creatinine, Uric acid and BUN significantly decreased from $104.26 \pm 7.45$ to $51.42 \pm 6.15, \quad 1.17 \pm 0.43$ to $0.62 \pm 0.14,3.68 \pm 1.34$ to $2.36 \pm 0.74$ and $48.72 \pm 4.36$ to $28.65 \pm 3.85$ respectively, in comparison to the nephrotoxic group of rats.

On administration of LD and HD of the macrofungal extract of $D$. spathularia, significant $(p<0.05)$ decrease in the concentration of these renal function parameters was observed, although these concentrations did not get back to their normal values completely but the decrement in the concentrations of renal function parameters was found significant, indicating the improvement in the renal profile of gentamicin-induced nephrotoxic animals. Table 2 shows the results of assessment of nephroprotective efficacy of $S$. commune extract. On administration of LD and HD of the macrofungal extract of $S$. commune, significant $(p<0.05)$ decrease in the concentration of renal function parameters was observed towards their normal values (Group 3 and 4), indicating the improvement in the renal profile of nephrotoxic animals. The results also revealed that the decrement of the renal function parameters on administration of $S$. commune extract was significantly more than that in case of administration of $D$. spathularia extract, 
indicating that $S$. commune has relatively more efficacy towards improvement of renal profile in gentamicin-induced nephrotoxicity in the present animal model in comparison to $D$. spathularia extract.

The improvement in renal profile in gentamicininduced nephrotoxicity in the present animal model by the administration of these two experimental edible macrofungi can be attributed to their significant antioxidant capacities against Reactive oxygen species like hydroxyl radical, super oxide ions etc. (Kumar et al., 2018). However, further research in this field can include the characterization and isolation of the exact biochemical constituent compounds in the two experimental macrofungi and their molecular mechanism of interactions to describe their role and pathways of their action in the improvement of renal profile of nephrotoxic animals, that has been found in the present work.

\section{Conclusion}

The present work revealed that both the experimental macrofungi have significant $(p<0.05)$ efficacy to improve the renal profile in gentamicininduced nephrotoxic rats. The $S$. commune was found to have more efficacy in improvement of renal profile of gentamicin-induced nephrotoxic rats, in comparison to $D$. spathularia extract, probably due to more antioxidant activities of $S$. commune in comparison to that of $D$. spathularia.

\section{ACKNOWLEDGEMENTS}

The authors acknowledge the facilities provided by the Deptt. Of Zoology, K.S. College, Seraikella and P.G. Departmentof Zoology, Ranchi University, Ranchi, Jharkhand, India

\section{REFERENCES}

1. Abdel-Raheem, I.T., Abdhal-Ghany, A.A., Mohamed, G.A. (2009). Protective effects of Quercetin against gentamicin-induced nephrotoxicity in rats. Biol. Pharm. Bull; 32(1):61-7.

2. Arivazhagan, S.J.J., Vimaastalin, R. (2014). Nephroprotective activity of Aristo lochia Indica leaf extract against gentamicin induced renal dysfunction. International Journal of Research in Biochemistry and Biophysics; 4(2):13-8.

3. Balakumar, P., Chakkarwar, V.A., Kumar, V., Jain, A., Reddy, J., Singh, M. (2008). Experimental models for nephropathy. J Renin Angiotensin Aldosterone Syst; 9(4):189-95.

4. Cuzzocrea, S., Mazzon, E., Dugo, L., Serraino, I., DiPaola, R., Britti, D., et al. (2002). A role for superoxide in gentamicin-mediated nephropathy in rats. Eur J Pharmacology; 450(1):67-76.

5. Erdem, A., Gundogan, N., Alp, U., and Kara, A. (2000). The protective effect of taurine against Gen.induced acute tubular necrosis in rats. Nephrol Dial.Transplant, 15:1175-82.

6. Gilbert, D.N. (2005) Aminoglycosides. In: Mandell GL, Bennett JE, Dolin R, editors. Principle and practices of infectious disease. $6^{\text {th }}$ ed. New York: Churchill Livingstone; p. 328.
7. Harlalka, G.V., Patil, C.R., Patil, M.R. (2007). Protective effects of Kalanchoe pinnata pers. (Crassulaceae) on gentamicin-induced nephrotoxicity in rats. Indian J Pharma-col; 39(4):201-5.

8. Kumar, A., Ali, S., Lal, S.B., Sinha, M.P. (2018). Mycochemical screening and determination of nutritive potency and antioxidant activity of edible macrofungi Dacryopinax spathularia and Schizophyllim commune. World J. of Pharm. Res., Vol. 7, Issue 16, 1311-1321.

9. Kumar, A., Kumar, M., Sinha, M.P. (2019). Hepatoprotective efficacy of edible macrofungi Dacryopinax spathularia (Scwein) and Schizophyllum commune (Fries) against Carbon tetrachloride induced hepatotoxicity in albino Wistar rats. J. of Appl.and Nat. Sc. 11(1): 62-65.

10.Lindequist, U., Niedermeyer, T.H., Julich, W.D. (2005). The pharmacological potential of mushrooms. Evid Based Complement Alternat Med 2:285-289.

11.Morales, A.I., Detaille, D., Prieto, M., Puente, A., Briones, E., Arevalo, M., et al. (2010). Metformin prevents experimental gentamicin-induced nephropathy by a mitochondria-dependent pathway. Kidney Int; 77(10):861-69.

12.Nair, Aiswarya, Rao Rashmi, R., Shenoy Preethi, J., Vinod Chandran, S., Teerthanath, Pai Sunil, B., Rakesh, K.B. (2018). Nephroprotective Effect of Aqueous Extract of Pimpinella anisum in Gentamicin Induced Nephrotoxicity in Wistar Rats. Pharmacogn J.; 10(3):403-407.

13.Organisation for Economic Cooperation and Development (2004). OECD guidelines for the testing of chemicals /section 4: Health effects test no. 423; Acute Oral Toxicity-AcuteTtoxic Class Method.

14. Ozbek E. (2012). Induction of oxidative stress in kidney. Int J Nephrol., 2012:1-9.

15.Pragati Srivastava, Rashmi Rao, R., Preethi, J. Shenoy, Poornima Ajay Manjrekar, Teerthanath, S., Bhuvaneshwari, S. (2018). Nephroprotective Effect of Anethum graveolens in a Murine Model of Gentamicin induced Nephrotoxicity. J Young Pharm, 2018; 10(2): 155-158.

16.Parlakpinar, H., Tasdemir, S., Polat, A., BayKarabulut, A., Vardi, N., Ucar, M., Acet, A. (2005). Protective role of caffeic acid phenethyl ester (cape) on gentamicin-induced acute renal toxicity in rats. Toxicology 207, 169-177.

17.Ramhariya R, Ganeshpurkar A, Ayachi C, Kanojia P, Bansal D, Dubey N. Ameliorative effect of rutin on gentamicin-induced nephrotoxicity in murine model. Austin J Pharmacol Ther 2015;3(1):1066e70.

18.Rodrigues FA, Prata MM, Oliveira IC, Alves NT, Freitas RE, Monteiro HS, et al. (2014). Gingerol fraction from Zingiber officinale protects against gentamicin-induced nephrotoxicity. Antimicrob Agents Chemother; 58(4):1872-78.

19.Reiter RJ, Tan D, Sainz RM, Mayo JC, Lopez-Burillo S. (2002). Melatonin: reducing the toxicity and increasing the efficacy of drugs. J Pharm Pharmacology; 54(10):1299-321.

20.Sener, G., Sehirli, A.O., Altunbas, H.Z., Ersoy, Y., Paskalylu, K., Arbak, S., Ayanoglu-Dulger, G. (2002). Melatonin protects against gentamicin-induced nephrotoxicity in rats. J. Pineal Res. 32 (4), 231-236.

21.Saud Alarifi, Amin Al-Doaiss, Saad Alkahtani, S.A. Al -Farraj, Mohammed Saad Al-Eissa, B. Al-Dahmash, Hamad Al-Yahya, Mohammed Mubarak (2012). Blood chemical changes and renal histological alterations induced by gentamicin in rats. Saudi Jr of Biol Sc. $19,103-110$ 